\title{
Penerapan Metode Multi Attribute Utility Theory (MAUT) Dalam Pemilihan Rumah Kost
}

\author{
Rita Novita Sari*1, Ratna Sri Hayati ${ }^{2}$ \\ Universitas Potensi Utama, Jl. K.L Yos Sudarso Km. 6,5 No. 3A \\ Program Studi Teknik Informatika, FTIK UPU, Medan \\ *1rita.ns89@gmail.com, ${ }^{2}$ ratnayach@gmail.com
}

\begin{abstract}
The development of information technology is currently developing rapidly. The use of information technology is very broad in various fields of life. The choice of boarding house is one of the things that is not easy to do. The problem often faced when choosing a boarding house is that boarders find it difficult to get information about boarding houses. Decision support system is a method that helps in making decisions on a particular problem, where no one can make a definite decision. Multi Attribute Utility Theory (MAUT) is a method of decision making. MAUT is a method where looking for weighted sums of the same values in each utility in each attribute. By applying the MAUT method in the selection of boarding houses, it can give good suggestions or recommendations on boarding houses.
\end{abstract}

Keywords: Bording House, Decision Support Systems, Methods Multi Attribute Utility Theory

\begin{abstract}
Abstrak
Perkembangan teknologi informasi saat ini sangat berkembang dengan cepat. Pemanfaatan teknologi informasi yang sangat luas dalam berbagai bidang kehidupan. Pemilihan rumah kost merupakan salah satu hal yang tidak mudah dilakukan. Masalah yang sering dihadapi ketika memilih rumah kost adalah para pencari rumah kost sulit mendapatkan informasi tentang rumah kost. Sistem pendukung keputusan adalah suatu metode yang membantu dalam pengambilan keputusan dalam suatu masalah tertentu, yang mana tidak seorangpun dapat mengambil keputusan secara pasti. Multi Attribute Utility Theory (MAUT) merupakan suatu metode dalam pengambilan keputusan. MAUT merupakan metode dimana mencari jumlah terbobot dari nilai- nilai yang sama pada setiap utilitas pada masingmasing atribut. Dengan menerapkan metode MAUT dalam pemilihan rumha kost dapat memberi saran atau rekomendasi rumah kost yang baik secara objektif.
\end{abstract}

Kata kunci: Rumah Kost, SPK, Multi Attribute Utility Theory

\section{PENDAHULUAN}

Perkembangan teknologi informasi saat ini sangat berkembang dengan cepat. Pemanfaatan yang sangat luas dalam berbagai bidang kehidupan. Dengan adanya teknologi informasi banyak memberikan kemudahan dalam segala aktivitas. Salah satunya dalam mencari informasi rumah kost. Kost dalam Kamus Besar Bahasa Indonesia adalah rumah kost yang berarti tempat tinggal dirumah orang lain dengan atau tanpa makan yang dibayar setiap bulan atau pertahun. Rumah kost sangat diperlukan untuk masyarakat yang sedang kuliah dan sedang bekerja yang jauh keluarga sehingga memerlukan rumah kost. Pemilihan rumah kost merupakan salah satu hal yang tidak mudah dilakukan. Masalah yang sering dihadapi ketika memilih rumah kost adalah para pencari rumah kost sulit mendapatkan informasi tentang rumah kost. Sistem pendukung keputusan adalah suatu metode yang membantu 
dalam pengambilan keputusan dalam suatu masalah tertentu, yang mana tidak seorangpun dapat mengambil keputusan secara pasti [1].

Multi Attribute Utility Theory (MAUT) merupakan suatu metode dalam pengambilan keputusan. MAUT merupakan metode dimana mencari jumlah terbobot dari nilai - nilai yang sama pada setiap utilitas pada masing masing atribut. Metode ini juga dapat memproses data dari semua atribut dengan utilitas - utilitas yang berbeda. Metode MAUT juga mampu membantu dalam mengambil keputusan dalam memilih rumah kost berdasarkan banyaknya jenis atribut - atribut yang berbeda. Metode MAUT juga memiliki banyak kelebihan salah satunya adalah rating kinerja pada setiap atribut (cost dan benefit) tidak perlu dilakukan normalisasi. Normalisasi, atribut dan utilitas dapat berdiri dengan sendiri - sendiri. Selama melakukan penelitian ini, penulis banyak membaca jurna - jurnal yang berkaitan dengan judul yang peulis akan teliti. Salah satunya penulis membaca jurnal yang dilakukan oleh putra aditya, dkk, dimana pada penelitian ini mereka membahas tentang pemilihan rumah kost di sekitar Universitas Brawijaya dengan menggunakan metode Analitycal Hierarchy Process (AHP) dan Simple Additive Weighting (SAW). Metode AHP digunakan untuk mengecek apakah bobot yang digunakan sudah konsisten atau belum, dan metode SAW digunakan untuk mendapatkan nilai prefrensi kemudian diurutkan agar kost yang direkomendasikan dimulai yang paling baik. Dari pengujian yang telah dilakukan bahwa jumlah kriteria sangatlah berpengaruh dalam hasil perangkingan. Kecocokan paling tinggi pada penelitian ini adalah 6 kriteria dengan persentase sebesar $8.83 \%$, untuk 5 kriteria diperoleh persentase sebesar 7.99\%, untuk 4 kriteria diperoleh persentase sebesar $4.76 \%$, untuk 3 kriteria diperoleh persentase sebesar 3.58\%, dan untuk kriteria 1 dan 2 diperoleh persentase sebesar $0 \%$ [2].

Selanjutnya penelitan yang dilakukan oleh Arif Hidayatullah di tahun 2019. Pada penelitian ini Arif membahas pemilihan rumah kost, disini Arif menggunakan metode MAUT dimana pada penelitian ini diharapkan dapat memberikan rekomendasi rumah kost sesuai dengan kriteria - kriteria yang sudah ditentukan. Sistem yang dibuat memberikan kemudahan kepada mahasiswa/i UNHASY dalam memilih rumah kost terbaik didaerah UNHASY [3]. Penelitian selanjutnya yang penulis baca adalah penelitian yang dilakukan oleh Erna Daniati ditahun 2015. Pada penelitian yang dilakukan oleh Erna membahas tentang pemilihan kost dengan menggunakan metode SAW. Penelitian ini berhasil membantu para pencari rumah kost lebih efektif dan efisien dalam mencari rumah kost [4]. Penelitian selanjutnya dilakukan oleh Herik Sugianto,dkk. Pada penelitian ini mereka membahas tentang pemilihan tempat kost khusus mahasiswa dengan menggunakan metode AHP dan Topsis berbasis WEB. Hasil dari penelitan yang telah dilakukan diperoleh 5 buat tempat kost terbaik kepada pengguna. Data ini diperoleh dengan membagikan kuesioner kepada 100 orang mahasiswa dan diperoleh hasil 83\% mahasiswa mengisi kuesioner dan memberikan tanggapan bahwa sistem yang dibuat membantu mereka dalam memperolah kost yang tepat 
[5]. Pada penelitian ini penulis menerapkan metode MAUT dalam sistem pendukung keputusan pemilihan rumah kost. Berdasarkan uraian diatas, penulis merancang sebuah "Sistem Pendukung Keputusan Pemilihan Rumah Kost Dengan Metode MAUT".

\section{METODE PENELITIAN}

Pada penelitian ini, peneliti menerapkan metode MAUT atau yang sering disebut metode penjumlahan terbobot. Dengan metode Multi Attribute Utility Theory (MAUT) sistem yang dibuat dapat menampilkan rekomendasi beberapa rumah kos sesuai dengan kriteria yang diinginkan oleh pengguna. Sehingga dari hasil tersebut bisa pencari rumah kost dalam mencari rumah kost dan menentukan pilihan rumah kost yang diinginkan oleh pengguna. Metode MAUT merupakan suatu skema dimana evaluasi total $V(x)$ dari setiap alternatif didefinisikan sebagai bobot yang dijumlahkan dengan nilai yang relevan dari nilai dimensinya [6]. Secara umum, metode MAUT adalah teknik untuk mendukung pengambilan keputusan ketika pembuat keputusan harus memilih dari beberapa alternatif. Alternatif bisa berupa tempat tinggal yang tersedia di wilayah tertentu [7]. Evaluasi total dapat dirumuskan sebagai berikut :

$\mathrm{V}(x)=\sum_{i=1}^{n} w_{i} \cdot v_{i}(x)$

dimana :

$\mathrm{V}(x)=$ Evaluasi total dari alternatif $\mathrm{x}$

$w_{i} \quad=$ Bobto relatif kretiria ke $-\mathrm{i}$

$v_{i}(x)=$ Hasil evaluasi kriteria ke $-\mathrm{i}$ dari alternatif $\mathrm{x}$

$i \quad=$ Indeks kriteria

Fungsi - fungsi utilitas untuk normalisasi setiap alternatif yang digunakan untuk mencari hasil dari evaluasi alternatif ke $-\mathrm{x}$, dalam skala $0-1$ disebut juga sebagai $U(x)$ yang dapat dilihat pada rumus (2) berikut ini :

$\mathrm{U}(x)=\frac{x-x_{1}^{-}}{x_{1}^{+}-x_{1}^{-}}$

dimana :

$\mathrm{U}(x)=$ Nilai utilitas dari alternatif ke $-\mathrm{x}$

$x_{1}^{-} \quad=$ Nilai terburuk dari kriteria ke $-\mathrm{i}$ di alternatif $\mathrm{x}$

$x_{1}^{+}=$Nilai terbaik dari kriteria ke $-\mathrm{i}$ di alternatif $\mathrm{x}$

Jika menggunakan aturan Schäfer maka tingkat kepentingan dari bobot adalah $=$

$1=$ Sangat Tidak Penting

$2=$ Tidak Penting

$3=$ Cukup Penting

$4=$ Penting

$5=$ Sangat Penting 
Untuk menghitung nilai bobot relatif pada setiap kriteria menggunakan rumus (3) sebagai berikut:

$w_{i}=\frac{w_{i}^{\prime}}{\sum w_{i}^{\prime}}$

dimana :

$w_{i} \quad=$ Bobot relatif kriteria ke $-\mathrm{i}$

$\sum w_{i}^{\prime}=$ Jumlah tingkat kepentingan bobot dari setiap kriteria

$w_{i}^{\prime} \quad=$ Jumlah tingkat kepentingan bobot dari setiap kriteria

Adapaun langkah - langkah metode MAUT adalah yaitu [8]:

1. Definisikan Alternatif dan Nilai dari Kriteria yang ada.

2. Klasifikasi semua alternatif secara terpisah dari setiap kriteria

3. Tetapkan bobot relatif pada setiap kriteria

4. Gabungkan bobot relatif dari setiap kriteria dan hasil evaluasi setiap kriteria dari semua alternatif untuk

5. memperoleh evaluasi total dari keseluruhan alternatif

6. Analisa hasil dari evaluasi total dari keseluruhan alternatif dan buat rekomendasi

Selanjutnya menetukan langkah - langkah yang dilakukan peneliti untuk menerapkan Metode MAUT dapat dilihat pada diagram flowchart pada gambar 1.

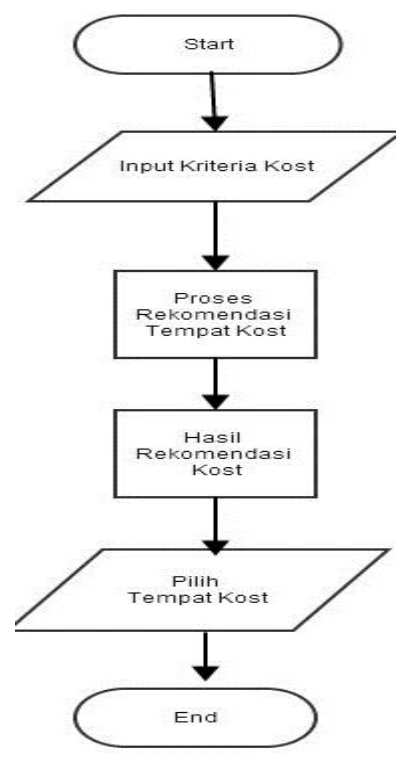

Gambar 1. Flowchart Proses Pencari Rumah Kost 


\section{HASIL DAN PEMBAHASAN}

Selanjutnya menentukan langkah - langkah yang dilakukan peneliti untuk menerapkan Metode MAUT dapat yaitu menentukan tingkat kepentingan pada kriteria berdasarkan nilai bobot yang dibuat. Kriteria kriteria ini yang akan digunakan untuk memilih rumah kost

a. Menentukan Alternatif

Pada penelitian ini terdapat 5 buah rumah kost yaitu Kost A, Kost B dan Kost C

b. Menentukan Kriteria dan Bobot dari Alternatif

Penentuan tingkat kepentingan disetiap kriteria berdasarkan nilai bobot, yang akan digunakan untuk memilih rumah kos adalah sebagai berikut :

Tabel 1. Kriteria dan Bobot

\begin{tabular}{|c|l|l|}
\hline No & \multicolumn{1}{|c|}{ Kriteria } & Bobot \\
\hline 1 & Harga sewa Kost (B1) & $0.25-0.9$ \\
\hline 2 & Lokasi Kost (B2) & $0.25-0.9$ \\
\hline 3 & Luas Rumah Kost(B3) & $0.25-0.9$ \\
\hline 4 & Fasilitas Utama Rumah Kost(B4) & $0.25-0.9$ \\
\hline 5 & Fasilitas Tambahan Rumah Kost(B5) & $0.25-0.9$ \\
\hline 6 & Kebersihan(B6) & $0.25-0.9$ \\
\hline 7 & Keamanan(B7) & $0.25-0.9$ \\
\hline 8 & Kondisi Bangungan(B8) & $0.25-0.9$ \\
\hline
\end{tabular}

Selanjutnya persepsi penilaian akan diberi penilaian :

TP : Tidak Penting $=0.25$

CP : Cukup Penting $=0.50$

$\mathrm{P} \quad$ : Penting $=0.75$

SP : Sangat Penting $=0.9$

Pada tabel 2 merupakan data penilain yang diperoleh dari pencari rumah kost yang telah diteliti.

Tabel 2. Penilaian Pencari Rumah Kost A

\begin{tabular}{|c|c|c|c|c|c|c|c|c|}
\hline Pencari Rumah Kost & B1 & B2 & B3 & B4 & B5 & B6 & B7 & B8 \\
\hline P1 & 0.85 & 0.70 & 0.52 & 0.65 & 0.5 & 0.65 & 0.90 & 0.75 \\
\hline P2 & 0.90 & 0.81 & 0.63 & 0.8 & 0.25 & 0.80 & 0.70 & 0.60 \\
\hline P3 & 0.85 & 0.85 & 0.28 & 0.7 & 0.3 & 0.74 & 0.70 & 0.50 \\
\hline P4 & 0.80 & 0.85 & 0.70 & 0.5 & 0.35 & 0.65 & 0.65 & 0.62 \\
\hline P5 & 0.75 & 0.75 & 0.66 & 0.6 & 0.6 & 0.55 & 0.62 & 0.25 \\
\hline P6 & 0.82 & 0.74 & 0.75 & 0.3 & 0.55 & 0.45 & 0.45 & 0.80 \\
\hline P7 & 0.90 & 0.62 & 0.59 & 0.35 & 0.68 & 0.77 & 0.75 & 0.45 \\
\hline P8 & 0.84 & 0.71 & 0.90 & 0.48 & 0.74 & 0.56 & 0.90 & 0.55 \\
\hline P9 & 0.80 & 0.82 & 0.74 & 0.47 & 0.55 & 0.78 & 0.85 & 0.63 \\
\hline P10 & 0.81 & 0.90 & 0.66 & 0.46 & 0.44 & 0.89 & 0.75 & 0.70 \\
\hline Rata - Rata & 0,83 & 0,79 & 0,80 & 0,53 & 0,50 & 0,35 & 0,78 & 0,64 \\
\hline
\end{tabular}


Tabel 3. Penilaian Pencari Rumah Kost B

\begin{tabular}{|c|c|c|c|c|c|c|c|c|}
\hline Pencari Rumah Kost & B1 & B2 & B3 & B4 & B5 & B6 & B7 & B8 \\
\hline P1 & 0.9 & 0.86 & 0.63 & 0.8 & 0.9 & 0.77 & 0.89 & 0.6 \\
\hline P2 & 0.75 & 0.9 & 0.28 & 0.7 & 0.55 & 0.56 & 0.65 & 0.5 \\
\hline P3 & 0.82 & 0.75 & 0.7 & 0.9 & 0.35 & 0.44 & 0.65 & 0.66 \\
\hline P4 & 0.78 & 0.85 & 0.65 & 0.7 & 0.45 & 0.47 & 0.62 & 0.75 \\
\hline P5 & 0.82 & 0.74 & 0.25 & 0.7 & 0.55 & 0.35 & 0.45 & 0.8 \\
\hline P6 & 0.9 & 0.65 & 0.6 & 0.46 & 0.75 & 0.8 & 0.5 & 0.45 \\
\hline P7 & 0.84 & 0.76 & 0.74 & 0.5 & 0.9 & 0.74 & 0.25 & 0.55 \\
\hline P8 & 0.8 & 0.84 & 0.74 & 0.6 & 0.3 & 0.65 & 0.85 & 0.63 \\
\hline P9 & 0.81 & 0.74 & 0.66 & 0.3 & 0.48 & 0.55 & 0.75 & 0.7 \\
\hline P10 & 0.82 & 0.79 & 0.8 & 0.36 & 0.36 & 0.35 & 0.78 & 0.64 \\
\hline Rata - Rata & 0,90 & 0,87 & 0,66 & 0,67 & 0,62 & 0,61 & 0,72 & 0,70 \\
\hline
\end{tabular}

Tabel 4. Penilaian Pencari Rumah Kost $\mathrm{C}$

\begin{tabular}{|c|c|c|c|c|c|c|c|c|}
\hline Pencari Rumah Kost & B1 & B2 & B3 & B4 & B5 & B6 & B7 & B8 \\
\hline P1 & 0.59 & 0.8 & 0.78 & 0.65 & 0.6 & 0.45 & 0.78 & 0.75 \\
\hline P2 & 0.9 & 0.86 & 0.82 & 0.8 & 0.74 & 0.77 & 0.89 & 0.9 \\
\hline P3 & 0.74 & 0.9 & 0.9 & 0.7 & 0.55 & 0.74 & 0.56 & 0.7 \\
\hline P4 & 0.66 & 0.75 & 0.84 & 0.25 & 0.44 & 0.65 & 0.9 & 0.65 \\
\hline P5 & 0.75 & 0.85 & 0.66 & 0.3 & 0.47 & 0.65 & 0.7 & 0.25 \\
\hline P6 & 0.75 & 0.74 & 0.75 & 0.48 & 0.8 & 0.25 & 0.7 & 0.8 \\
\hline P7 & 0.28 & 0.65 & 0.75 & 0.46 & 0.81 & 0.65 & 0.8 & 0.45 \\
\hline P8 & 0.7 & 0.76 & 0.9 & 0.5 & 0.35 & 0.65 & 0.9 & 0.55 \\
\hline P9 & 0.8 & 0.84 & 0.75 & 0.6 & 0.45 & 0.62 & 0.85 & 0.63 \\
\hline P10 & 0.81 & 0.74 & 0.82 & 0.3 & 0.55 & 0.45 & 0.75 & 0.7 \\
\hline Rata - Rata & 0,77 & 0,87 & 0,85 & 0,57 & 0,64 & 0,63 & 0,86 & 0,71 \\
\hline
\end{tabular}

Selanjutnya penulis membuat bobot preferensi dari setiap kriteria pada masing - masing rumah kost sebagai berikut :

$\begin{array}{ll}\text { Harga sewa kost } & : 0.35 \\ \text { Lokasi Kost } & : 0.2 \\ \text { Luas Rumah Kost } & : 0.05 \\ \text { Fasilitas Utama Rumah Kost } & : 0.1 \\ \text { Fasilitas Tambahan Rumah Kost } & : 0.05 \\ \text { Kebersihan } & : 0.1 \\ \text { Keamanan } & : 0.1 \\ \text { Kondisi Bangungan } & : 0.05\end{array}$

Selanjutnya dilakukan perhitungan dengan menggunakan metode MAUT

Tabel 5. Normalisasi Matriks dan Bobot Preferensi

\begin{tabular}{|c|c|c|c|c|c|c|c|c|}
\hline Rumah Kost & B1 & B2 & B3 & B4 & B5 & B6 & B7 & B8 \\
\hline Rumah Kost A & 0,83 & 0,79 & 0,80 & 0,53 & 0,50 & 0,35 & 0,78 & 0,64 \\
\hline Rumah Kost B & 0,90 & 0,87 & 0,66 & 0,67 & 0,62 & 0,61 & 0,72 & 0,70 \\
\hline Rumah Kost C & 0,77 & 0,87 & 0,85 & 0,57 & 0,64 & 0,63 & 0,86 & 0,71 \\
\hline Bobot Preferensi & $\mathbf{0 , 3 5}$ & $\mathbf{0 , 2}$ & $\mathbf{0 , 0 5}$ & $\mathbf{0 , 1}$ & $\mathbf{0 , 0 5}$ & $\mathbf{0 , 1}$ & $\mathbf{0 , 1}$ & $\mathbf{0 , 0 5}$ \\
\hline
\end{tabular}


Selanjutnya Normalisasi Matriks Pemiliha Rumah Kost didapat dengan menggunakan persamaan (2) :

\section{Rumah Kost A}

$\begin{array}{llll}\text { Kost } A_{1} & =\frac{0.83-0.77}{0.90-0.77}=\frac{0.06}{0.13}=0.46 & \text { Kost } A_{5} & =\frac{0.50-0.50}{0.64-0.50}=\frac{0}{0.14}=0 \\ \text { Kost } A_{2} & =\frac{0.79-0.79}{0.87-0.79}=\frac{0}{0.08}=0 & \text { Kost } A_{6} & =\frac{0.78-0.72}{0.86-0.72}=\frac{0.06}{0.14}=1 \\ \text { Kost } A_{3} & =\frac{0.80-0.66}{0.80-0.66}=\frac{0.14}{0.14}=1 & \text { Kost } A_{7} & =\frac{0.78-0.72}{0.86-0.72}=\frac{0.13}{0.13}=0.42 \\ \text { Kost } A_{4} & =\frac{0.53-0.53}{0.67-0.53}=\frac{0}{0.14}=0 & \text { Kost } A_{8} & =\frac{0.64-0.64}{0.71-0.64}=\frac{0.13}{0.13}=1\end{array}$

\section{Rumah Kost B}

Kost $B_{1}=\frac{0.90-0.77}{0.90-0.77}=\frac{0.13}{0.13}=1$
Kost $B_{2}=\frac{0.87-0.79}{0.87-0.79}=\frac{0.08}{0.08}=1$
Kost $B_{3}=\frac{0.66-0.66}{0.85-0.66}=\frac{0}{0.19}=0$
Kost $B_{4}=\frac{0.67-0.53}{0.67-0.53}=\frac{0.14}{0.14}=1$

Kost $\mathrm{B}_{5}=\frac{0.62-0.50}{0.64-0.50}=\frac{0.12}{0.14}=0.85$

Kost $\mathrm{B}_{6}=\frac{0.61-0.35}{0.63-0.35}=\frac{0.26}{0.28}=0.92$

Kost $\mathrm{B}_{7}=\frac{0.72-0.72}{0.86-0.72}=\frac{0}{0.14}=0$

Kost $B_{8}=\frac{0.70-0.64}{0.71-0.64}=\frac{0.06}{0.07}=0.85$

\section{Rumah Kost C}

Kost $\mathrm{C}_{1}=\frac{0.77-0.77}{0.90-0.77}=\frac{0}{0.13}=0$

Kost $C_{2}=\frac{0.87-0.79}{0.87-0.79}=\frac{0.08}{0.08}=1$

Kost $C_{3}=\frac{0.85-0.66}{0.85-0.66}=\frac{0.19}{0.19}=1$

Kost $\mathrm{C}_{4}=\frac{0.57-0.53}{0.67-0.53}=\frac{0.04}{0.14}=0.28$

$$
\begin{aligned}
& \text { Kost } C_{5}=\frac{0.64-0.50}{0.64-0.50}=\frac{0.14}{0.14}=1 \\
& \text { Kost } C_{6}=\frac{0.63-0.35}{0.63-0.35}=\frac{0.28}{0.28}=1 \\
& \text { Kost } C_{7}=\frac{0.86-0.72}{0.86-0.72}=\frac{0.14}{0.14}=1 \\
& \text { Kost } C_{8}=\frac{0.71-0.64}{0.71-0.64}=\frac{0.07}{0.07}=1
\end{aligned}
$$

Tabel 6. Hasil Normalisasi Matriks

\begin{tabular}{|c|c|c|c|c|c|c|c|c|}
\hline Rumah Kost & B1 & B2 & B3 & B4 & B5 & B6 & B7 & B8 \\
\hline Rumah Kost A & 0.46 & 0 & 1 & 0 & 0 & 1 & 0.42 & 1 \\
\hline Rumah Kost B & 1 & 1 & 0 & 1 & 0.85 & 0.92 & 0 & 0.85 \\
\hline Rumah Kost C & 0 & 1 & 1 & 0.28 & 1 & 1 & 1 & 1 \\
\hline
\end{tabular}

Setelah hasil normalisasi matriks kita dapatkan, langkah selanjutnya kita lakukan perkalian hasil normalisasi matriks dengan bobot prefernsi yang sudah kita buat dengan menggunakan persamaan (1) :

\section{Rumah Kost A}

$$
\begin{aligned}
& =(0.35 * 0.46)+(0.2 * 0)+(0.05 * 1)+(0.1 * 0.28)+(0.05 * 1)+(0.1 * 1)+ \\
& (0.1 * 1)+(0.05 * 1) \\
& =(0.16+0+0.05+0.028+0.05+0.1+0.1+0.05) \\
& =0.54
\end{aligned}
$$




\section{Rumah Kost B}

$=(0.35 * 1)+(0.2 * 1)+(0.05 * 0)+(0.1 * 1)+(0.05 * 0.85)+(0.1 * 0.92)+$ $(0.1 * 0)+(0.05 * 0.85)$

$=(0.35+0.2+0+0.1+0.04+0.09+0.1+0.05)$

$=0.93$

\section{Rumah Kost $\mathbf{C}=$}

$(0.35 * 0)+(0.2 * 1)+(0.05 * 1)+(0.1 * 0.28)+(0.05 * 1)+(0.1 * 1)+(0.1 *$

1) $+(0.05 * 1)$

$=(0+0.2+0.05+0.03+0.05+0.1+0.1+0.05)$

$=0.58$

Dari persamaan (1) yang sudah dilakukan perhitungan maka diperoleh hasil perkalian dari matrik normalisasi yang dapat dari dilihat pada tabel 7 berikut ini

Tabel 7. Hasil Perkalian Matrik Ternormalisasi Dengan Bobot Preferensi

\begin{tabular}{|c|c|c|}
\hline Rumah Kost & Hasil & Peringkat \\
\hline Rumah Kost A & 0.54 & 3 \\
\hline Rumah Kost B & 0.96 & 2 \\
\hline Rumah Kost C & 0.58 & 1 \\
\hline
\end{tabular}

Dari hasil perhitungan yang sudah didapat dengan menggunakan metode MAUT pada pencarian rumah kost diperoleh hasil penilaian yang objektif dimana pada rumah kost B memiliki nilai terbaik yaitu 0.96 , rumah kost $C$ memiliki nilai sebesar 0.58 dan rumah kost $\mathrm{C}$ memeiliki nilai sebesar 0.54

\section{SIMPULAN}

Dari hasil penelitian yang dilakukan, maka peneliti dapat menyimpulkan bahwa :

a. Dengan menerapkan metode MAUT dalam pemilihan rumha kost dapat memberi saran atau rekomendasi rumah kost yang baik secara objektif.

b. Dari hasil perhitungan diperoleh rumah kost B memiliki nilai terbaik yaitu sebesar 0.96 , rumah kost $C$ memiliki nilai sebesar 0.58 dan rumah kost A memiliki nilai sebesar 0.54.

\section{UCAPAN TERIMA KASIH}

Peneliti mengucapkan terima kasih kepada pihak Kementerian Riset Teknologi Dan Pendidikan Tinggi Republik Indonesia (KEMENRISTEKDIKTI) yang telah mendanai penelitian ini. 


\section{DAFTAR PUSTAKA}

[1] Sukaria, Petra Nugra. 2017. System Pendukung Keputusan Pemilihan Mobil Bekas Berbasis Web menggunakan Metode Multi Attribute Utility Theory (MAUT). Skripsi prodi S1 Teknik Informatika Universitas Sanata Dharma Yogyakarta

[2] Primanda, Putra Aditya., Edy Santoso., Tri Afirianto, Pemilihan Kost di Sekitar Universitas Brawijaya menggunakan Metode Analitycal Hierarchy Process (AHP) dan Simple Additive Weighting (SAW), Jurnal Pengembangan Teknologi Informasi dan Ilmu Komputer, Vol. 2, No. 6, Juni 2018, hlm. 20942103, e-ISSN: 2548-964X

[3] Hidayatullah, Arif, Sistem Pemilihan Rumah Kos Terbaik Di Sekitar Unhasy Dengan Metode Multi Attribute Utility Theory (Maut) Berbasis WEB, INOVATE. Volume 03 Nomor 02 Tahun 2019

[4] Daniati, Erna, Sistem Pendukung Keputusan Pemilihan Kost Di Sekitar Kampus Unp Kediri Menggunakan Metode Simple Additive Weighting (SAW), Seminar Nasional Teknologi Informasi dan Multimedia 2015, ISSN : 2302-3805

[5] Sugiatno, Herik., Yulianti., Hengky Anra, Sistem Pendukung Keputusan Pemilihan Tempat Kost Khusus Mahasiswa dengan Metode AHP dan TOPSIS Berbasis Web (Studi Kasus : Kota Pontianak), Jurnal Sistem dan Teknologi Informasi (JUSTIN) Vol. 1, No. 1, (2016)

[6] Eklesiano, Jen. 2018. Sistem Pendukung Keputusan Pemberian Kredit Berbasis Web menggunakan Metode Multi Attribute Utility Theory (MAUT). Skripsi prodi S1 Teknik Informatika Universitas Sanata Dharma Yogyakarta

[7] Sylvia, J.T. Jansen. 2011. The Measurement and Analysis of Housing Preference And Choice, Delft University of Technology, Delft, The Netherlands. 